\title{
Laparoscopic Pielolitotomy: An option for the management of pelvic kidney stones
}

\author{
Artur de Oliveira Paludo ${ }^{1}$, Antonio Rebello Horta Gorgen ${ }^{1}$, Marcio Araldi ${ }^{1}$, Patric Machado Tavares ${ }^{1}$, \\ Nelson Sivonei Batezini ${ }^{1}$, Tiago Elias Rosito ${ }^{1,2}$ \\ ${ }^{1}$ Hospital de Clinicas de Porto Alegre, Porto Alegre, RS, Brasil; ${ }^{2}$ Universidade Federal do Rio \\ Grande do Sul-UFRS, Porto Alegre, RS, Brasil
}

\section{ABSTRACT}

Introduction: Minimally invasive treatments such as extracorporeal shock wave lithotripsy and percutaneous nephrolithotripsy are standard procedures for the management of renal stones (1). However, renal position and rotation defects may significantly interfere in the results of these treatments (2). Open surgery has always been an option for these cases, but with the advancement of laparoscopy in the last decades, laparoscopic pielolitotomy has become a good alternative for approaching kidney stones in abnormal renal rotation and position (3).

Materials and methods: A 42-year-old male patient with a $2.2 \mathrm{~cm}$ stone in the left pelvic kidney was submitted to laparoscopic pielolitotomy after extracorporeal schok wave lithotripsy failure and difficulty in access for percutaneous nephrolithotripsy. We did not have access to flexible ureteroscopy for this case.

Results: The surgical time was 150 minutes. An antegrade JJ stent was inserted and renal pelvic suture was performed with vicryl 4-0. There was no need for opioids and patient was discharged on the first postoperative day. The JJ stent was removed after 1 month, with complete resolution of the clinical symptoms.

Conclusions: Laparoscopic pielolitotomy is an excellent treatment alternative for patients with large stones in pelvic kidney.

\section{CONFLICT OF INTEREST}

None declared.

\section{REFERENCES}

1. Ahangar S, Durrani AM, Qadri SJ, Patloo AM, Ganaie RG, Khan M. Laparoscopic trans-peritoneal pyelolithotomy in a pelvic kidney. Saudi J Kidney Dis Transpl. 2012;23:1254-7.

2. Hoenig DM, Shalhav AL, Elbahnasy AM, McDougall EM, Clayman RV. Laparoscopic pyelolithotomy in a pelvic kidney: a case report and review of the literature. JSLS. 1997;1:163-5.

3. Kamat N, Khandelwal P. Laparoscopic pyelolithotomy---a technique for the management of stones in the ectopic pelvic kidney. Int $\mathrm{J}$ Urol. 2004;11:581-4. 
ARTICLE INFO

(iD) Artur de Oliveira Paludo

https://orcid.org/0000-0002-0701-3301

Available at: http://www.intbrazjurol.com.br/video-section/20190148_Paludo_et_al

Int Braz J Urol. 2020; 46 (Video \#14): 489-90

Submitted for publication:

February 27, 2019

Correspondence address:

Artur de Oliveira Paludo, MD

Accepted after revision:

August 16, 2019

Hospital de Clínicas de Porto Alegre Rua: Ramiro Barcelos, 2350/Sala 835

Porto Alegre, RS, Brasil

Published as Ahead of Print:

E-mail: arturpaludo@gmail.com

December 30, 2019 